\title{
EFFECTS OF BUTTER OIL AND WHEY PROTEINS ADDITION ON VISCOELASTIC PROPERTIES OF CONFECTIONARY DULCE DE LECHE
}

\author{
M.L. OLIVARES ${ }^{\dagger}$, M.S. PAULETTI ${ }^{*}$, S.C. COSTA ${ }^{\ddagger}$, \\ D. DE PIANTE VICÍN ${ }^{\dagger}$ and A.C. RUBIOLO ${ }^{\dagger}$ \\ ${ }^{\dagger}$ Instituto de Desarrollo Tecnológico para la Industria Química (UNL-CONICET)-Santa Fe-Argentina \\ olivares@santafe-conicet.gov.ar \\ * Instituto de Tecnología de Alimentos (UNL)-Santa Fe-Argentina
}

\begin{abstract}
The effect of butter oil and whey proteins addition on viscoelastic properties of confectionary Dulce de Leche was evaluated. A two factors experimental design (0-8 \% p/v of butter oil and 0-1 $\% \mathbf{p} / \mathbf{v}$ of whey proteins) was analysed. Frequency sweep tests were carried out and for all formulations studied a weak gel like behavior was observed. Therefore, results were interpreted using a weak gel model for foods. It was observed that the rheological behavior of the sample with addition of whey proteins and butter oil is significantly different than the others because rheological units interact with greater strength. Even more, the sample without butter oil and with whey proteins addition is composed by less rheological units than the others. It is concluded that the whole addition of butter oil and whey proteins generates a stronger gel matrix, more appropriate for use in confectionary.
\end{abstract} teins

Keywords-dulce de leche, rheology, whey pro-

\section{INTRODUCTION}

Dulce de Leche (DL) is a sweet spread widely consumed as jam and as dessert. Also, is widely used in bakery and confectionery in the preparation of desserts and cakes as a cram. Argentina produces about 140,000 tons per year and $5.5 \%$ of this production is exported to several countries (Ministerio de Ganadería, Agricultura, Pesca y Alimentos de la República Argentina, 2012).

Argentinean food legislation (Código Alimentario Argentino, 2013) defines DL as "the product obtained by heat concentration, at normal or reduced pressure, of milk or reconstituted milk apt for human consumption, with the addition of white sugar". Small amounts of sodium bicarbonate is also added which increases the $\mathrm{pH}$ of the final product and avoids protein coagulation. Vanillin is added as flavouring agent (Rovedo et al., 1991; Navarro et al., 1999). Maillard browning reactions occurs during this process; therefore the product has a distinctive brown colour (Navarro et al., 1999).

The heat treatment applied during DL manufacture generates chemical modifications leading to irreversible aggregation with formation of a gel with particular characteristics (Pauletti et al., 1996). The resulting mixture of carbohydrates, proteins and fats determines its structural properties, affecting its functional characteristics (Ranalli et al., 2012). For confectionery uses a firm texture is needed and for these purposes different hydrocolloids are used. Therefore, rheological characterization can be used as a quality control tool because the rheological parameters may be related to the desirable texture of confectionary DL.

The earliest studies related to DL texture were carried out using shear viscometry (Moro and Hough, 1985; Hough and Moro 1988; Rovedo et al. 1991; Heimlich et al. 1994). These authors reported that DL presents a pseudoplastic behavior and it can be described by Casson's and Herschel-Bulkley models. In addition, Pauletti et al. (1990) and Navarro et al. (1999) studied different types of DL by oscillatory rheometry and observed that its rheological behavior is intermediate between a concentrated solution and a gel, depending on the type of DL and the solid content. Recently, Ranalli et al. (2012) analyzed the physicochemical properties of four types of commercial DL (traditional, reduced calories, reduced fat and confectionary) and developed a comprehensive study on the viscoelastic behavior of these products. This behavior was modeled using the Baumgartel-Scahusberger-Winter (BSW) and the mechanical relaxation spectrum in the linear viscoelastic range was predicted. The parameters of the BSW model were used to explain structural characteristics of the systems and, the dynamic data measured was also successfully converted into time and was validated using creep and flow experiments.

Whey proteins, a byproduct from cheese and casein manufacture, are frequently used as functional ingredients in many foods. They are now widely used as gelling agents, emulsifiers, texture modifiers, thickening agents and foaming agents. In addition, they have high nutritive value and are generally recognized as safe (Bryant and Mc Clements, 1998; Meza et al., 2010). Whey proteins ingredients may be purchased in several different forms. Whey proteins concentrates (WPC) contain between $20 \%$ and $89 \%$ of protein, being WPC with $35 \%$ of protein content the most common product (Tunick, 2008; Meza et al., 2010). In this sense, results of technological interest to explore the potential use of WPC as texture modifier in DL formulation and as fat replacer. Therefore, the objective of this work was to study the effect of whey proteins concentrate (WPC) and butter oil addition on viscoelastic properties of confectionary DL. 


\section{METHODS}

\section{A. Dulce de Leche samples preparation}

Skim milk powder (Milkaut, Frank, Argentina), sucrose (Ledesma, Jujuy, Argentina), butter oil (Corlasa, Esperanza, Argentina) and a $35 \% \mathrm{w} / \mathrm{w}$ whey protein concentrate (Milkaut, Frank, Argentina) were used as ingredients for DL manufacture. In addition, carrageenan (Carragel, Gaiman, Argentina) and agar-agar (Chubutagar, Gaiman, Argentina) were used as thickening agents. Different DL samples were prepared, as listed in Table 1. Partial hydrolysis of lactose was carried out in order to avoid lactose crystallization by the addition of $0.015 \mathrm{~kg}$ of a commercial $\beta$-galactosidase enzyme extract (Maxilact, Delft, Holland) to the reconstituted milk at $37^{\circ} \mathrm{C}$, one hour before manufacture.

The manufacture of each sample was carried out in an open kettle commonly used by the industry. The ingredients were mixed; the $\mathrm{pH}$ was fixed at 6.9 by addition of $\mathrm{Ca}(\mathrm{OH})_{2}$ p.a. and then, the mixture was concentrated at atmospheric pressure up to $70^{\circ} \mathrm{Brix}$. A refractometer (ATAGO Master H80, Tokyo, Japan) was used for the measurement of ${ }^{\circ}$ Brix during the concentration process. The obtained product was cooled at $70^{\circ} \mathrm{C}$, packaged in containers of $250 \mathrm{~g}$ and storage for a week at room temperature prior analysis.

As minimal variability between batches was observed previously (Pauletti et al., 1990, 1995), this study was carried out considering one batch of Dulce de Leche for each sample in order to significantly reduce the number of assays.

\section{B. Rheometrical measurements}

A rheometer Haake RheoStress RS80 (Haake Instrument Inc., Paramus, NJ, USA) with parallel plates (35 $\mathrm{mm}$ diameter, $1 \mathrm{~mm}$ gap) was used for rheometrical measurements. The temperature of the lower plate was maintained at $25^{\circ} \mathrm{C}$ by circulating water from water bath. The DL sample was placed on the lower plate and then the upper plate was brought in contact with the sample to attain temperature equilibrium.

The dynamic rheological data obtained included the 2 components of complex shear modulus $\left(G^{*}\right)$ : the storage modulus $\left(G^{\prime}\right)$, which is a measure of the energy stored and recovered per cycle of deformation (elastic component), and the loss modulus $\left(G^{\prime \prime}\right)$, which is a measure of the energy dissipated or lost as heat per cycle of deformation (viscous component) (Gunasekan and $\mathrm{Ak}, 2003$ ). These parameters are related as follows:

Table 1. Dulce de Leche samples studied.

\begin{tabular}{ccccc}
\hline Ingredient & \multicolumn{4}{c}{ Samples } \\
& S1 & S2 & S3 & S4 \\
\hline Tap water (kg) & 27 & 27 & 27 & 27 \\
Skimmed milk & 2.74 & 2.74 & 2.74 & 2.74 \\
powder (kg) & & & & \\
Sucrose (kg) & 7.2 & 7.2 & 7.2 & 7.2 \\
Whey Proteins & 0 & 1 & 1 & 0 \\
$\quad \%$ w/w) & & & & \\
Butter oil (\% w/w) & 0 & 0 & 8 & 8 \\
Carrageenan (kg) & 0.015 & 0.015 & 0.015 & 0.015 \\
Agar-agar (kg) & 0.01 & 0.01 & 0.01 & 0.01 \\
\hline
\end{tabular}

$$
\left|G^{*}\right|^{2}=\left(G^{\prime}\right)^{2}+\left(G^{\prime \prime}\right)^{2}
$$

Frequency sweep tests were carried out from 0.01 to 1 $\mathrm{Hz}$ at strain amplitude of $0.01 \pm 5 \times 10^{-4}$. The linear viscoelastic region was determined by performing strain sweep tests from 0.001 to 0.1 at $25^{\circ} \mathrm{C}$ for all samples studied. Moreover, the effect frequency on complex viscosity $\left(\left|\eta^{*}\right|=\left|\mathrm{G}^{*}\right| / \omega, \omega\right.$ : frequency of oscillation) was analysed. Each sample was analysed in triplicate.

\section{Data modelling}

Frequency dependency of $\left|\mathrm{G}^{*}\right|$ for the DL samples was fitted by the weak gel model for foods (Gabriele et al., 2001), in which the structure of the material is modelled as a cooperative arrangement of flow units, to form a strand. According to this model, the complex modulus can be expressed by:

$$
\left|G^{*}\right|=\sqrt{\left(G^{\prime}\right)^{2}+\left(G^{\prime \prime}\right)^{2}}=A_{F} \omega^{1 / z}
$$

Where $z$ is the interaction factor and $A_{F}$ is the gel strength. Values of $z$ can be interpreted as the number of flow units interacting with one another in a threedimensional structure to give the observed flow response of the material; $A_{F}$ can be interpreted as the strength of the interaction between flow units.

\section{Statistical analysis}

Data were analysed by ANOVA using Statgraphics (Statgraphics Inc., Rockville, MD, USA). When differences between treatment effects were significant $(P<0.05)$, a multiple comparison of means was performed.

\section{RESULTS AND DISCUSSION}

Figure 1 shows changes in $\mathrm{G}^{\prime}, \mathrm{G}^{\prime}$ ' as function of frequency of DL samples. In samples S1, S3 and S4 the magnitudes of G' were higher than G' without exhibiting no crossing point and both increased with increased in frequency, indicating dominant elastic properties. In sample S2 G' and G' also increased with increased in frequency but their values were similar in the whole frequency range evaluated, indicating similar elastic and viscous character $\left(G^{\prime} \sim G^{\prime}\right.$ '). In addition, $G^{\prime}$ and $G^{\prime}$ ' values of the sample $\mathrm{S} 2$ were lower than those obtained from the other samples analysed. From a structure point of view, for true gels $\ln \left(\mathrm{G}^{\prime}, \mathrm{G}^{\prime}\right.$ ') versus $\ln \omega$ plots have zero slope because the molecular rearrangements within the network are very reduced over the time scales analysed, while there are positive slopes and $G^{\prime}$ is greater than $G$ ', over a whole frequency ranges of $\omega$ studied for weak gels and highly concentrated dispersions (Rao, 1999).

In weak gels there is a higher dependence on frequency for the dynamic moduli, suggesting the existence of relaxation processes occurring even at short time scales, and lower difference between moduli values, indicating that a lower percentage of the stored energy is recovered (Rao, 1999). Therefore, mechanical spectra of all DL samples denote a weak gel structure. These findings are in agreement with those reported by Navarro et al. (1999) and Ranalli et al. (2012). 

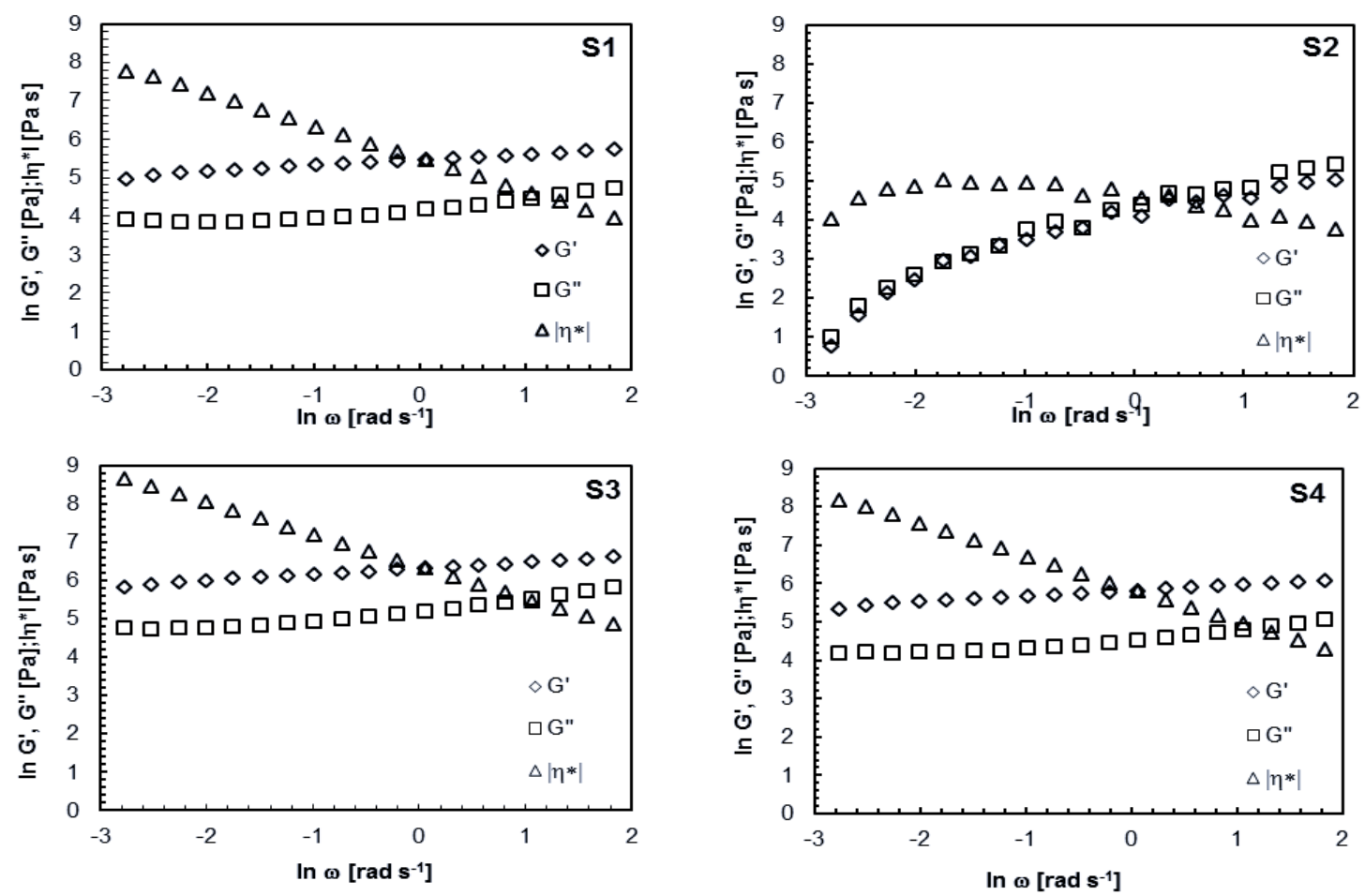

Figure 1. Characteristics frequency sweeps of DL samples studied.

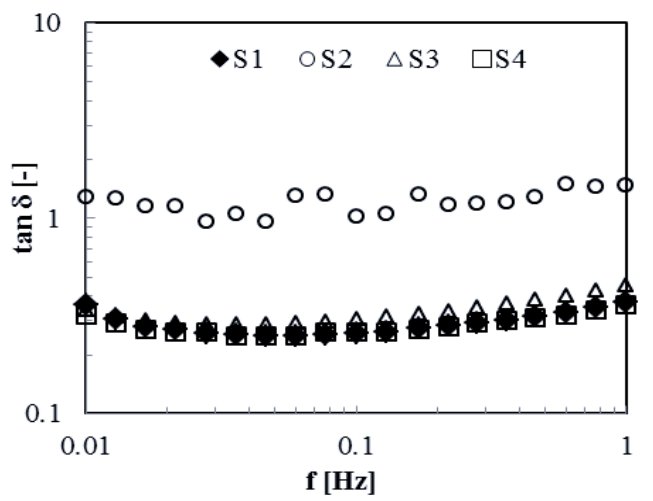

Figure 2. Characteristic loss tangent $(\tan \delta)$ as function of frequency corresponding to DL samples studied.

The total resistance to flow of a material considered to be a viscous liquid refers to complex viscosity $\left(\left|\eta^{*}\right|\right)$ (Dimitreli and Thomareis, 2008). Fig. 1 also shows that $\left|\eta^{*}\right|$ of samples S1, S3 and S4 decreases across the frequency range which indicates shear-thinning behaviour. However, $\left|\eta^{*}\right|$ values of sample S2 were lower and less shear-thinning behaviour was observed.

Another useful rheometrical function in describing viscoelastic behaviour is the loss tangent ( $\tan$ $\left.\delta=\mathrm{G}^{\prime \prime} / \mathrm{G}^{\prime}\right)$. It is dimensionless and gives a clear indication of whether the material behaves as solid-like or liquid-like. The larger the $\tan \delta$ value, the more easily the DL flows. These results are presented in Fig. 2. The loss tangent values showed a predominantly elastic behaviour $(\tan \delta<1)$ in samples S1, S3, S4 over the whole range of frequency tested while a slightly viscous behaviour was observed in sample S2 $(\tan \delta>1)$. As it can be seen, the loss tangent clearly differentiated the viscoelastic behaviour in two groups of samples. For samples S1, S3 y S4 tan $\delta$ presented values between 0.2 and 0.3 that correspond to amorphous polymers (Steffe, 1996). These values were also reported by Ranalli et al. (2012) for commercial DL. For sample S2 $\tan \delta$ presented values between 0.9 and 1.4 that may correspond to a concentrated solutions or weak gels.

Therefore, in order to analyse the overall rheological behaviour, the response of complex modulus $\left(\left|\mathrm{G}^{*}\right|\right)$ of DL samples was compared with the weak gel model for foods (Gabriele et al., 2001). Figure 3 shows characteristics experimental data and the fitted values obtained with Eq. (2), giving for all frequency sweeps analysed a fitting error less than 5\%. The obtained rheological parameters are listed in Table 2.

ANOVA indicated that the sample with whey proteins addition and without butter oil (S2) presented less number of rheological units than the others $(z)$. This suggests that the structure of sample S2 is composed by less number of junction's zones in the network, generating a weaker matrix. The sample with addition of whey proteins and butter oil (S3) had a rheological behaviour significantly different than the others because presented higher gel strength between rheological units quantified by the parameter $A_{F}$. Therefore, the whole addition of butter oil and whey proteins in sample S3 generates a stronger gel matrix. 


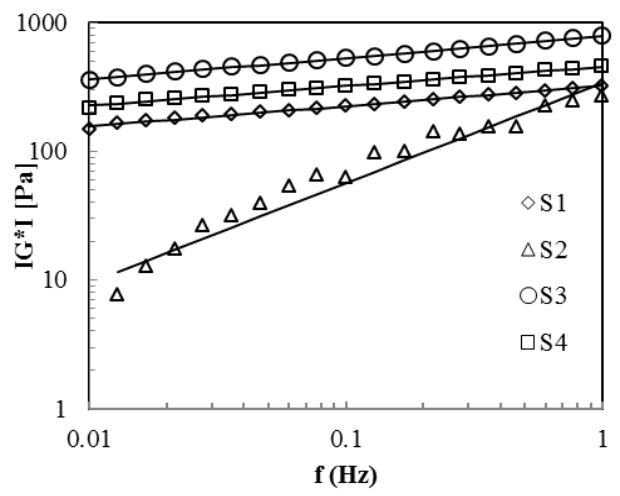

Figure 3. Complex modulus $\left(\left|\mathrm{G}^{*}\right|\right)$ as function of frequency of DL samples. Symbols are experimental values and lines correspond to predictions carried out with the weak gel model for foods.

Table 2. Mean values of weak gel model parameters of DL samples*

\begin{tabular}{ccc}
\hline Sample & $\left.A_{f \cdot\left[\mathrm{Pa}^{\mathrm{z}}\right]}\right]$ & $z[-]$ \\
\hline S1 & $336.7^{\mathrm{a}}$ & $6.6^{\mathrm{b}, \mathrm{c}}$ \\
S2 & $309.1^{\mathrm{a}}$ & $1.7^{\mathrm{a}}$ \\
S3 & $695.7^{\mathrm{b}}$ & $6.1^{\mathrm{b}}$ \\
S4 & $344.8^{\mathrm{a}}$ & $6.8^{\mathrm{c}}$ \\
\hline
\end{tabular}

* Mean values with different letters in a column indicate significant differences $(P<0.05)$.

\section{CONCLUSION}

It is concluded that mechanical spectra of all DL samples studied denote a weak gel structure. The DL microstructure significantly changes with whey proteins and butter oil addition. When whey proteins are presents in absent of butter oil, the dynamic moduli of DL presented higher dependency of frequency, suggesting a weaker matrix. This phenomenon was also observed when complex modulus of DL samples was compared with the weak gel model for foods. This model indicated that the structure of sample S2 is composed by less number of junction's zones in the network. The whole addition of butter oil and whey proteins in S3 generates a stronger gel matrix, more appropriate for use in confectionary.

\section{REFERENCES}

Bryant, C.M. and D.J. McClements, "Molecular basis of protein functionality with special consideration of cold-set gels derived from heat-denatured whey," Trends Food Sci Tech, 9, 143-151 (1998).

Código Alimentario Argentino, Available from: www. anmat.gov.ar/alimentos/codigoa/CAPITULO_VIII. pdf. Accessed january 2 (2013).

Dimitreli, G. and A.S. Thomareis, "Effect of chemical composition on the linear viscoelastic properties of spreadable-type processed cheese," Journal of Food Eng, 84, 368-374 (2008).

Gabriele, D., B. De Cindio and P. D'Antona, “A weak gel model for foods," Rheol Acta, 40, 120-127 (2001)
Gunasekaran, S. and M.M. Ak, Cheese Rheology and Texture, CRC Press, Boca Raton (2003).

Heimlich, W., R. Bórquez and I. Céspedes, "Effect of milk replacement by whey protein concentrates on the rheological properties of dulce de leche," Food Sci Technol-LEB, 27, 289-29 (1994).

Hough G. and O. Moro, "Flow properties of dulce de leche, a typical Argentine dairy product", J. Dairy Sci, 71, 1783-1788 (1988).

Meza, B.E., R.A. Verdini and A.C. Rubiolo, "Effect of freezing on the viscoelastic behaviour of whey protein concentrate suspensions," Food Hydrocolloids, 24, 414-423 (2010).

Ministerio de Ganadería, Agricultura, Pesca y Alimentos de la República Argentina, Available from: http://www.minagri.gob.ar. Accessed: august 27 (2012).

Moro, O. and G. Hough, "Total solids and density measurements of dulce de leche, a typical Argentine Dairy product," J. Dairy Sci, 68, 521-525 (1985).

Navarro, A.S., C. Ferrero and N.E. Zaritzky, "Rheological characterization of "Dulce de Leche" by dynamic and steady shear measurements," J. Texture Stud., 30, $43-58$ (1999).

Pauletti M.S., A. Venier, N. Sabbag and D. Stecchina "Rheological Characterization of dulce de leche, a confectionery dairy product," J. of Dairy Sci., 73, 601-603 (1990).

Pauletti M.S., E.L. Castelao, N. Sabbag and S. Costa. "Color development rate in dulce de leche," Food Sci Technol Int., 1, 137-140 (1995).

Pauletti, M.S., E.L. Castelao and E. Seguro, "Kinetics of heat coagulation of concentrated milk proteins at high sucrose contents," J. Food Sci, 61, 1207-1210 (1996).

Ranalli, N., S.C. Andrés and A.N. Califano, "Physicochemical and rheological characterization of dulce de leche", J.Texture Stud., 43, 115-123 (2012).

Rao, M.A., Rheology of fluids and semisolid foods. Principles and applications, Gaithersburg, Aspen (1999).

Rovedo, C.O., P.E. Viollaz and C. Suarez, "The effect of $\mathrm{pH}$ and temperature on the rheological behavior of dulce de leche, a typical dairy argentine product," J. Dairy Sci, 74, 1497-1502 (1991).

Steeffe, J.F., RheologicalMethods in Food Processing Engineering, 2nd Ed. Freeman Press, East Lansing (1996).

Tunick, M.H. Whey protein production and utilization: a brief history. In C. I. Onwulata and P. J. Huth (Eds.), Whey processing, functionality and health benefit, John Wiley \& Sons, Iowa (2008).

Received: March 27, 2013

Accepted: November 6, 2013

Recommended by Subject Editor: María Luján Ferreira 